\title{
Sleep in Autism Spectrum Disorders
}

\author{
Olivia J. Veatch $^{1}$ • Angela C. Maxwell-Horn ${ }^{2}$ • Beth A. Malow ${ }^{1}$
}

Published online: 24 April 2015

(C) Springer International Publishing AG 2015

\begin{abstract}
Autism spectrum disorders (ASD) are common neurodevelopmental conditions, affecting 1 in 68 children. Sleep disturbance, particularly insomnia, is very common in children diagnosed with ASD, with evidence supporting overlapping neurobiological and genetic underpinnings. Disturbed sleep exacerbates core and related ASD symptoms and has a substantial negative impact on the entire family. Treatment of sleep disturbance holds promise for ameliorating many of the challenging behavioral symptoms that children with ASD and their families face. Behavioral and pharmacological studies indicate promising approaches to treating sleep disturbances in this population. Awareness of treatment options is particularly important as parents and clinicians may believe that sleep disturbance is part of autism and refractory to therapy. In addition, autism symptoms refractory to treatment with conventional psychiatric medications may improve when sleep is addressed. Additional evidence-based studies are needed, including those that address the underlying biology of this condition.
\end{abstract}

This article is part of the Topical Collection on Sleep and Psychological Disorders

Beth A. Malow

beth.malow@vanderbilt.edu

Olivia J. Veatch

olivia.j.veatch@vanderbilt.edu

Angela C. Maxwell-Horn

angela.c.maxwell-horn@vanderbilt.edu

1 Sleep Disorders Division, Department of Neurology, Vanderbilt University Medical Center, 1161 21st Avenue South, Room A-0116, Nashville, TN 37232-2551, USA

2 Department of Developmental Medicine, Vanderbilt University Medical Center, Monroe Carell Children's Hospital, 11101 DOT, Nashville, TN 37232, USA
Keywords Pediatric sleep disorders · Autism . Neurodevelopmental disorders $\cdot$ Diagnosis $\cdot$ Behavioral therapy $\cdot$ Pharmacotherapy $\cdot$ Genetics $\cdot$ Biochemistry

\section{Introduction}

Autism spectrum disorders (ASD), whose core features are impairments in social communication and the presence of restricted and repetitive behaviors [1], are common with a prevalence of 1 in 68 children [2]. In children with ASD, approximately $50-80 \%$ have disturbed sleep, primarily related to sleep onset or sleep maintenance insomnia [3-5]. This high prevalence is in contrast to $11-37 \%$ in children of typical development $[6,7]$. While the relationship of sleep disturbance to challenging daytime behaviors (e.g., attention deficit hyperactivity disorder symptomatology) has been established in typically developing children [8], those with ASD may be even more vulnerable to the detrimental effects of sleep disruption on daytime behavior given their neurodevelopmental condition. Sleep problems in children with ASD have been associated with more internalizing and externalizing behavior problems and poorer adaptive skill development [9]. In our work, poor sleepers with ASD (defined by parent report, polysomnography, and actigraphy) had more inattention, hyperactivity, and restricted/repetitive behaviors [10].

In this review, we evaluate the current literature related to sleep problems in children with ASD and their treatment, with reference to the biological mechanisms underlying expression of both of these neurological conditions.

\section{Causes and Categories of Sleep Problems in Individuals with ASD}

Sleep problems in ASD have a broad differential, and are often multifactorial. Table 1 provides an overview of the different causes, as well as the categories. In this section, 
Table 1 Causes and categories of sleep problems common in children with ASD

Causes of sleep problems
-Neurobiological
-Medical, including psychiatric and medications
-Behavioral
Categories of sleep problems
-Insomnia
-Sleep disordered breathing
-Sleep-related movement disorders
-Parasomnias
-Sleepwalking, sleep terrors, confusional arousals
-Nightmares
-REM sleep behavior disorder
-Bruxism

we discuss first the broad causes of sleep problems in ASD. We then discuss the categories of sleep problems in this population, including insomnia, circadian rhythm disorders, sleep disordered breathing, sleep-related movement disorders, and parasomnias.

\section{Causes of Sleep Problems in ASD}

While there is natural overlap among these causes, it is helpful to consider sleep problems in ASD as being neurobiological, medical, or behavioral in origin. The neurobiological causes can be thought of as relating to genetic or neurotransmitter abnormalities shared by sleep and autism (e.g., abnormalities in the melatonin pathway) and are discussed in the subsequent section "Overlapping Mechanisms between Sleep and ASD". The medical causes include a variety of conditions common in ASD, including epilepsy and gastrointestinal disturbances that disrupt sleep. Psychiatric conditions, including depression, anxiety, and attention deficit hyperactivity disorder, which are also more common in ASD, can be included with these causes, although we acknowledge they have clear neurobiological underpinnings. Medications used to treat medical and psychiatric conditions can also be included with these causes, as many of these medications (e.g., fluoxetine) tend to be stimulating and disrupt sleep. Finally, the behavioral category includes behaviors that are related to the ASD phenotype, such as resistance transitioning from daytime activities to nighttime activities, difficulty understanding what is expected at bedtime, and preferences for using electronic devices (which inhibit sleep).

\section{Categories of Sleep Problems in ASD}

\section{Insomnia-Parent Report and Objective Measures}

Insomnia, defined as difficulty falling asleep or staying asleep, is the most common sleep problem reported by parents in studies employing questionnaire data $[4,11]$. While the literature has focused on children with ASD, reports in adults have found similar findings [12]. Only a few studies have looked at objective polysomnographic or actigraphic data to evaluate the sleep of individuals with ASD. For the most part, these studies have confirmed parent report, although there have been some discrepancies, which may reflect differences in methodology related to collection of data, or clinical heterogeneity in the sample studied. Souders et al. found that the prevalence of sleep problems by actigraphy was comparable to that of parent report [5]. Malow et al., examining polysomnography results, found longer sleep latencies and lower sleep efficiency in children with ASD who were reported by their parents to be "poor sleepers" compared to the "good sleepers," these results were comparable to children of typical development without sleep problems [13]. Allik et al. also found concordance between actigraphy and parent report in children with ASD [14].

In contrast, Wiggs and Stores [15] did not find any actigraphic differences in children with ASD with and without parent-reported sleep problems. However, when they pooled the data and compared them to a control group of typically developing children whose actigraphy data was available in a database, they did find some notable differences. The children with ASD often fell asleep later, woke up more during the night, and awakened either very early or very late [15].

\section{Rapid Eye Movement Differences}

The amount of time spent in rapid eye movement (REM) sleep has also received attention, especially given the role of REM sleep in memory consolidation [16]. As noted above, few studies have performed polysomnography in ASD. Buckley et al. conducted a one-night polysomnographic study and compared PSG data between children with ASD, developmental delay, and typical development. Their study found that, as compared to typically developing children, those with ASD had a lower percentage of REM sleep [17].

Conversely, Malow et al. found no significant difference in REM sleep in children with ASD versus typically developing children on night two of polysomnography [13]. Another study evaluating adults with high functioning ASD also found no difference in REM sleep versus controls [18]. It is possible that the Buckley et al. finding of decreased REM sleep following only one-night of polysomnography was confounded by sleep being more disrupted on the first night of a laboratory-based study as many children with ASD have 
difficulty sleeping in an unfamiliar environment. However, a subsequent study from this group evaluating the first night effect in children with ASD found no difference between PSG recordings measured on night one compared to night two [17]. Further study of REM sleep in ASD appears warranted.

\section{Circadian Rhythm Disorders}

It is difficult to differentiate whether delayed sleep is due to insomnia, or a delayed sleep phase circadian rhythm disorder (or potentially both disorders) as circadian rhythm disorders in children with ASD often do not fit traditional ICSD3 diagnostic criteria [19]. For example, a child may have delayed sleep onset but also wake early and have multiple wakings throughout the night. These features are atypical for classic delayed sleep phase disorder which is characterized by delayed wake time and normal sleep continuity. Social cues, to which children with ASD may be less attuned because of their decreased awareness of social cues, are important synchronizers of circadian rhythms. Children with ASD have been postulated to be vulnerable to circadian rhythm disturbances (see review by [20]) [20]. Distinguishing between circadian factors and insomnia can be quite challenging, especially given the biological and environmental factors that contribute to both disorders.

Another challenge is related to sleep duration. Importantly, there are no finite amounts of sleep that are considered ideal for individuals with ASD. While guidelines have been established for children with typical development [21, 22], it is still unclear whether children with ASD require more, less, or similar amounts of sleep compared to typically developing peers. In fact, what are considered adequate sleep durations in children with ASD is an important area of controversy. Many studies have indicated that children with ASD on average sleep less during the night compared to children of typical development. The largest prospective, longitudinal study to date indicates that total sleep duration in children with ASD is reduced compared to typically developing peers from 30 months of age, persisting into adolescence [23]. However, the fact that these children slept less does not give any indication into what should be considered an adequate amount of sleep, which likely varies from child to child.

\section{Sleep Disordered Breathing}

Whether or not children with ASD are more prone to sleep disordered breathing (SDB) is unclear. One study found no polysomnographic differences in sleep apnea indices for individuals with or without autism [18] and another study identified sleep apnea in only 1 of 21 children with ASD [13], comparable with prevalence rates in general pediatrics of 1$5 \%$ [24].
However, even if SDB is equally common in children with ASD than in those of typical development, children with ASD may still stand to benefit from improvement in their sleep patterns. This is an area where more research is warranted, especially given evidence of improvements in behavior and quality of life when SDB is treated in children of typical development [25]. Malow et al. [13] observed that for the child with ASD who also had SDB, symptoms of social communication, attention, and repetitive behaviors improved after adenotonsillectomy [13]. However, we have also encountered in our clinical experience children with ASD whose problematic behaviors (e.g., irritability, aggression) worsened after adenotonsillectomy, likely reflecting removal of the sedating effects of SDB.

\section{Sleep-Related Movement Disorders}

Movement disorders during sleep relevant to ASD include the following: rhythmic movement disorder and restless legs syndrome (RLS) along with periodic limb movements in sleep (PLMS) and periodic limb movement disorder [19]. Rhythmic movement disorder is characterized by repetitive movements of the extremities, trunk, or head that often occurs during the transition from wake to sleep [26]. These sleep-related movements may resemble self-stimulatory behaviors during wakefulness, and there is likely overlap among these behaviors. The differential diagnosis for sleep-related movement disorders (SRMDs) includes epileptic seizures. Clinicians observing these events may also confuse them with psychogenic events.

RLS is characterized by an uncomfortable feeling in the legs which is worse at night or when lying down, and relieved by movement. A related condition, periodic limb movements in sleep, is characterized by repetitive movements of the extremities during sleep. Periodic limb movement disorder, which is rarer than periodic limb movements in sleep, is characterized by these movements but has accompanying sequelae, such as sleepiness during the day.

RLS is already difficult to diagnose in children of typical development who have great difficulties in describing their symptoms [27]. This diagnostic complexity is compounded when one is trying to diagnose these conditions in a child with ASD and communication challenges. In our experience, even a highly verbal child will often have difficulty trying to communicate an "uncomfortable feeling". We are dependent on observant parents and astute physicians to unravel exactly what the child is experiencing and how their symptoms are manifesting, and to combine other supportive data to assist with the diagnosis, such as behavioral observations, as well as family history, low normal ferritin levels $(<50 \mathrm{ng} / \mathrm{ml})$, and periodic limb movements on an overnight PSG [28]. 


\section{Parasomnias}

Parasomnias are undesired events that happen during sleep. Events encompass sleep walking, sleep terrors, confusional arousals, nightmares, REM sleep behavior disorder, and bruxism [19]. Several studies have found that parasomnias may be more common in children with ASD versus controls [29-31]. In fact, parental questionnaires have a very high positive predictive value in diagnosing parasomnias in children [30]. One of the shortcomings of parent questionnaires in diagnosing parasomnias is that night wakings related to insomnia may not be easily differentiated from parasomnias. Therefore, it is important to follow-up questionnaire findings with a thorough sleep history that assesses the level of consciousness and responsiveness of the child during a night waking. REM sleep behavior disorder was reported to be common in ASD in one case series [32], although the REM sleep without atonia that characterizes REM sleep behavior disorder was not noted in other PSG studies in ASD [13, 17, 18].

\section{Overlapping Mechanisms Between Sleep and ASD}

In this section, we will review genetic and biological mechanisms implicated in sleep traits, and in the sleep disorders that are most commonly observed in individuals with ASD. Further, we compare these with the mechanisms that have also been implicated in risk for ASD. Evidence suggests strong genetic susceptibility factors underlying ASD. The sibling recurrence risk is estimated at 45-90 times greater than the population risk. Current estimates from twin studies indicate 58$60 \%$ of monozygotic twins are concordant for the full syndrome and 50-90\% are concordant for related social or cognitive abnormalities [33, 34]. Interestingly, the known biological functions for recurrently implicated ASD candidate genes suggest involvement of shared molecular pathways with sleep regulation.

\section{Biology and Genetics of Sleep and Sleep Disorders Related to ASD}

\section{Normal Sleep}

The molecular genetics of sleep timing as a function of circadian rhythm oscillations is well established [35] and will not be discussed outside of the relevance to ASD. The involvement of the circadian system in ASD was first proposed in 2002, when it was suggested that anomalies in genes operating as "timing" genes in this high frequency oscillator system may underlie the timing and social deficits that are fundamental to ASD [36]. Significant allelic associations with ASD have been detected for variation in the PER 1 and NPAS2 genes [37], which are involved in regulation of the circadian system.
Since these initial studies, numerous overlapping biological mechanisms involved in sleep regulation and ASD have been identified. Multiple neurotransmitters including serotonin, dopamine, norepinephrine, and gamma-aminobutyric acid (GABA) are involved in homeostatic regulation of sleep [38] and implicated in the etiology of ASD [39-41]. The dopamine transporter has been implicated in regulation of sleep homeostasis [42], with recent work showing that the presence of a de novo mutation in the dopamine transporter gene DAT1, identified in one child with ASD, causes hyperactive behavior in model organisms [43]. Furthermore, some of the most consistently replicated genes harboring common variants related to ASD include the SLC6A4 gene encoding the serotonin transporter and the $G A B R B 3$ gene encoding a ligand-gated gamma-aminobutyric acid receptor [44]. The involvement of these neurotransmitter systems in expression of specific sleep disorders is detailed further below.

\section{Insomnia}

Basic science studies have implicated effects on risk for insomnia from numerous molecular mechanisms that overlap with mechanisms predicted to contribute to risk for ASD (Table 2). In addition, the current heritability estimates for insomnia range between $21-64 \%$, evidence that genetic factors are involved [53]. For example, the GABAergic system has been strongly implicated in ASD and insomnia. The GABAergic system is critical to cortical development, suggesting that the neurodevelopmental defects observed in ASD may be partially attributed to abnormalities in the GABAergic system [54]. A region of chromosome 15 at the GABRB3 locus, 15q11-13, was observed to have recurrent copy number variations in a substantial proportion of individuals with ASD $[46,55]$, and variations in the GABA-R $\gamma 3$ gene were also found to be associated with ASD risk [46]. A mutation in the gene encoding the GABA-A beta 3 subunit was identified in patients with chronic insomnia, supporting the hypothesis that a decrease in GABAergic inhibition may contribute to insomnia [45]. In addition, functional proton magnetic resonance spectroscopy data has indicated that children with ASD have lower levels of GABA in multiple cortical regions compared to typically developing children. Regions include the frontal lobes [56], auditory cortex [57], and other motor and auditory regions of interest [41]. Similar findings reporting globally reduced levels of GABA in the brain were observed in individuals with chronic insomnia $[58,59]$, further support for a biological connection between insomnia and ASD.

Serotonin is another neurotransmitter involved in both ASD and sleep. Evidence supporting an involvement of the serotonergic signaling system in ASD includes increased levels of whole-blood serotonin [60], altered serotonin synthesis [61], variation in the serotonin transporter gene (SLC6A4) 
Table 2 Overview of sleep disorders having overlapping mechanisms with ASD. Listed for each sleep disorder are the implicated biological mechanisms that are also thought to be involved in ASD. If there are specific genes that have been identified for both disorders, these are included with corresponding references

\begin{tabular}{lll}
\hline Sleep disorder & Biological mechanism & Gene \\
\hline Insomnia & GABAergic inhibition & GABA3 Buhr et al. [45], Shao et al. [46] \\
& Serotonergic transmission & SLC6A4 Deuschle et al. [47], Prasad et al. [48] \\
& Melatonergic system & AANAT Wang et al. [49], Hu et al. [50] \\
Sleep-related movement disorders & Dopaminergic transmission & DRD2 Connor et al. [51], Comings et al. [52] \\
& Iron metabolism & No specific shared risk genes \\
\hline
\end{tabular}

[48], and variation in the monoamine oxidase A gene (MAOA) which is responsible for serotonin degradation [62]. Serotonin is thought to be involved in promoting wakefulness and inhibiting REM sleep [63]. More recently, a connection between genetic variation in the serotonin transporter and insomnia was identified [47].

Serotonin is also a precursor for melatonin. Melatonin is synthesized in the pineal gland and its secretion is observed to have sedative effects that contribute to sleep onset [64]. Melatonin is also involved in many functional processes other than regulating the sleep-wake cycle in humans, including neurodevelopment [65]. Interestingly, the most consistent results reporting abnormal circadian rhythms in ASD concern the melatonin synthesis pathway [66]. Dysregulation of the melatonin pathway has been observed in some individuals with ASD, compared to normally developing controls. These individuals have exhibited lower levels of the major metabolite of melatonin, 6sulfoxymelatonin [67], and decreased nocturnal [68, 69] and daytime [70] blood melatonin levels. However, a more recent report documented normal overnight blood melatonin profiles in children with ASD and sleep onset delay responsive to supplemental melatonin [95]. Variation in numerous melatonin pathway genes has been predicted to increase risk for ASD. These include the gene encoding the rate-limiting melatonin pathway enzyme responsible for $N$-acetylation of serotonin, arylalkylamine $(A A N A T)[49,50]$, and the gene encoding the enzyme which subsequently converts serotonin to melatonin [71], acetylserotonin $O$ methyltransferase (ASMT) [70, 72, 73]. Melatonin is primarily metabolized by the liver enzyme, cytochrome P450 1A2 (CYP1A2) [74]. A potential relationship has also been implicated between presence of predicted slow-metabolizing alleles in CYP1A2 and susceptibility to ASD with comorbid sleep problems [75, 76]. In particular, we observed that expression of insomnia in ASD, and response to supplemental melatonin treatment, is potentially related to dysfunctional variation in both of these melatonin pathway genes. A mechanism was implicated connecting lower levels of ASMT transcript production with reduced CYP1A2 metabolic activity in children with ASD and comorbid sleep onset delay [76]; the net result may be normal nocturnal blood melatonin levels in these children.

\section{Sleep-Related Movement Disorders}

Restless leg syndrome (RLS) is a movement disorder having strong evidence for contributions from genetic factors [77]. Furthermore, it is well-established that there is a connection between iron and RLS, and more recently, a connection between dopamine and RLS has been indicated [28, 78]. Brain iron levels have been observed to be lower in individuals with RLS compared to controls [79]. Interestingly, iron deficiency and iron deficiency anemia have been observed to be more common in children with global developmental delay and/or ASD than in the general population [80]. A connection between low serum ferritin and sleep disturbance in children with ASD was also suggested based on a treatment trial showing that for a majority of children with ASD and restless sleep, iron therapy was effective at improving sleep [81].

In addition, neuropathological studies of patients with RLS have shown significant decreases in dopamine (DA) D2 receptors in the putamen. This tissue-specific decrease in dopamine receptors was also shown to be correlated with severity of RLS symptoms [51]. An abnormally activated dopaminergic system was also observed in both in vivo and in vitro models of iron insufficiency suggesting that for some RLS patients, there may be a connection between iron and dopamine that is central to the pathophysiology [28, 82]. Disrupted DA function is implicated in a number of neuropsychiatric disorders, including ASD, and it is thought that alterations in DA homeostasis may confer risk for $\mathrm{ASD}$ and related neuropsychiatric conditions. Specifically, the gene encoding the DAD2 receptors $(D R D 2)$ has been implicated in a number of behavioral disorders (Table 2) [52]. 


\section{Treating Sleep Problems in Individuals with Autism Spectrum Disorders}

Given the high prevalence of ASD and of dysregulated sleep in children with ASD, the need for effective treatments is critical for the health and well-being of the child and family. Furthermore, disrupted sleep may exacerbate core impairments of ASD.

Many of the behaviors that are associated with ASD (e.g., hypersensitivity to environmental stimuli, repetitive behaviors and/or thoughts, difficulty understanding social and/or communication cues) likely contribute to a child with ASD also having disturbed sleep. Therefore, implementing sleep education and behavioral strategies should be the first-line treatment for sleep problems in children with ASD once other medical and psychiatric issues have been addressed.

A practice pathway [83] emphasized that pharmaceutical interventions should be considered only after treatment with behavioral strategies is either unsuccessful, or when the strategies are not possible to implement without the short-term aid of a medication. Prior to use of pharmaceutical agents for treatment of a sleep disturbance in a child with ASD, it is also very important to conduct a thorough sleep history and comprehensively address all possible comorbid medical and psychiatric conditions. Many conditions that are associated with ASD (e.g., ADHD, obsessive compulsive disorder, depression, biopolar disorder, epilepsy) are known to affect sleep [84].

In addition, many medications that are prescribed to treat ASD symptoms and comorbid psychiatric conditions also affect sleep; some of the most commonly reported adverse events are insomnia or hypersomnolence [85]. For example, atypical antipsychotics have been evaluated and approved for treating aggressive or self-injurious behavior, severe mood swings, tantrums, and irritability in individuals with ASD. A commonly prescribed, and well-studied, atypical antipsychotic in ASD is risperidone [86]. The primary action of this molecule is serotonin 5-HT2 receptor blockade. It is also a potent dopamine D2 receptor antagonist [87]. One of the most commonly reported side effects for treatment with risperidone is daytime sleepiness; insomnia may also occur. In addition, uncontrolled weight gain may contribute to sleep apnea [88]. Selective serotonin reuptake inhibitors (SSRIs) are also often used for treating repetitive behaviors in ASD, and are known to regulate peripheral and central nervous system serotonin levels [89]. SSRI use has also been shown to have negative effects on sleep including insomnia [90].

\section{Behavioral Sleep Interventions}

Behavioral approaches to improving sleep start with proper bedtime practices, referred to as sleep hygiene. Proper sleep hygiene is composed of activities that make it easier to fall asleep and stay asleep. This includes having a cool, dark environment for sleep and eliminating caffeine ingestion. A soothing, "wind-down" routine before bed often helps relax the body and prepare for bed [91].

It is important to note that what might be relaxing for one child and therefore part of their "wind-down" routine, might actually be activating for another child. For example, one child might relax and calm down when placed in a warm bath. Another child, however, may be stimulated by bath time. Therefore, each child's bedtime routine should be individualized with activities that are calming and promote sleep for that particular child.

The use of electronic devices before bed should be discouraged if at all possible. Electronic devices such as televisions, cell phones, and video gaming devices emit background light. The light emitted from such devices suppresses endogenous melatonin production, which is critical for sleep initiation. Furthermore, the content provided by videos and other devices is often stimulating. It should be noted that in our experience, some children find that playing a game on a parent's phone or watching a video is actually calming before bed. In such cases, the brightness on the screen of the device should be adjusted so that the minimal amount of background light that is necessary for viewing is emitted.

\section{Pharmacological and Other Interventions}

\section{Insomnia}

Melatonin supplementation is an emerging approach to treating comorbid insomnia in children with ASD. This treatment strategy has been shown to be effective at improving sleep initiation with minimal reports of adverse events [92-96]. Melatonin is primarily used as a sedative at low doses (1 to $3 \mathrm{mgs}$ ) given approximately $30 \mathrm{~min}$ prior to bedtime. However, exogenous melatonin supplementation has also been observed to effectively treat circadian rhythm sleep disorders (i.e., abnormal sleep timing). In this case, melatonin is given at specific time-points based on the goal of shifting or advancing the timing of sleep onset (e.g., 3-5 h before bedtime for delayed sleep onset). Given that the half-life of melatonin is rather short $(<1 \mathrm{~h})$, it is less effective for night wakings [97]; controlled-release melatonin preparations are sometimes effective for night wakings [98].

When behavioral therapies and melatonin are ineffective, additional pharmacologic treatment may be considered. A few psychotropic medications have been evaluated for treating insomnia in children with ASD in retrospective, or small open-label trials [83]. These include clonidine [99], mirtazapine [100], and gabapentin [101]. Risperidone was also shown in another study to improve sleep-onset latency, but not sleep duration [102]; however, the side effects and other sleep-related health risks mentioned previously that relate to risperidone treatment indicate this medication should 
not be recommended solely for insomnia. Some medications that are prescribed to treat coexisting neurological conditions in children with ASD have sedating effects that promote sleep. When possible, it may be beneficial to choose a medication for the coexisting condition that will concurrently assist with sleep onset and maintenance [84]. For example, in a child with ASD and comorbid epilepsy, treatment with a sedating antiepileptic medication may also promote sleep maintenance in children with ASD.

\section{Sleep Disordered Breathing}

The majority of non-behavioral treatments for pediatric SDB include medical devices and surgical interventions. The surgical and first-line treatment of choice for pediatric OSA is usually adenotonsillectomy [103, 104]. Some children require continuous positive airway pressure (CPAP) or additional surgical procedures after adenotonsillectomy, particularly obese children and those with underlying medical conditions such as craniofacial anomalies [105]. For instance, children with syndromic ASD may be at higher risk for requiring further treatment following an adenotonsillectomy.

CPAP delivered via a nasal interface is the most common non-surgical therapy for pediatric OSAs in typically developing children. However, poor adherence can be a significant limitation of this treatment [106]. This may be particularly relevant in children with ASD given their sensory sensitivities [107]. There may, however, be opportunities through desensitization strategies to treat these children [108]. Effective methods of desensitization in children with ASD and developmental delay are still relatively unknown and an area for future work.

Other treatment options include rapid maxillary expansion [109], weight loss [110], and positional therapy [111]. Medication management for OSA includes nasal corticosteroids, leukotriene antagonists, and possibly a combination of the two [112-114]. However, medications should not be the primary treatment for OSA, especially in children with ASD as all of the current evidence for these treatments is limited and exclusively in children with typical development [115]. Effective pharmacological treatment options for OSA in children with ASD are an area requiring further research.

\section{Sleep-Related Movement Disorders}

It is well-known that PLMS have been related to low serum ferritin. Further discussion of this relationship was provided in the previous section on overlapping mechanisms. Iron deficiency may be more relevant in the ASD population due to often observed dietary restrictions [116]. While it is still not clear whether children with ASD have lower serum ferritin compared with typically developing peers, children with lower endogenous serum ferritin levels may benefit from iron supplementation [117].

It should be noted that use of certain medications, like SSRIs, can also provoke periodic limb movements, potentially leading to sleep fragmentation [118]. In addition, there are a variety of SRMDs that a child with ASD may manifest including tics and periodic limb movements related to treatment with atypical antipsychotics.

Rhythmic movement disorder is challenging to treat with medications but in our experience, may respond to the proprioceptive input provided by a soft helmet. This helmet also serves to protect the head from injury.

\section{Parasomnias}

Treatments are mostly limited to benzodiazepines and tricyclic antidepressants $[119,120]$. It is important to recognize that a primary diagnosis is key to effectively treating parasomnias. Parasomnias often present as night wakings in children with ASD. In our work, we have observed that when a child with ASD has been diagnosed with a true parasomnia, clonazepam is effective, but in children with other types of night wakings, it is less effective. To accurately diagnose a parasomnia, it can be very helpful to review home videos, and when appropriate perform a sleep study with extended EEG, particularly if seizures are a concern.

\section{Conclusions}

The combined research in sleep and ASD highlights the intrinsic complexity of these neurological disorders. While challenging to identify unifying themes and establish reliable genotype-phenotype relationships, there has been substantial progress in understanding the biology underlying both sleep and ASD. To understand how these findings contribute to disease processes and to identify more effective treatments for sleep disturbances in children with ASD, further functional characterization of the overlap across many shared underlying genetic and biological mechanisms is necessary.

\section{Compliance with Ethics Guidelines}

Conflict of Interest Olivia J. Veatch, Angela C. Maxwell-Horn declare that they have no conflict of interest. Beth A. Malow has received grants from Autism Speaks.

Human and Animal Rights and Informed Consent This article does not contain any studies with human or animal subjects performed by any of the authors. 


\section{References}

1. American Psychiatric Association. Report of DSM-5 proposed criteria for autism spectrum disorder designed to provide more accurate diagnosis and treatment. 2013.

2. CDC. Prevalence of autism spectrum disorder among children aged 8 years - autism and developmental disabilities monitoring network, 11 sites, United States, 2010. MMWR Surveill Summ. 2014;63:1-21.

3. Couturier JL, Speechley KN, Steele M, Norman R, Stringer B, Nicolson R. Parental perception of sleep problems in children of normal intelligence with pervasive developmental disorders: prevalence, severity, and pattern. J Am Acad Child Adolesc Psychiatry. 2005;44:815-22.

4. Krakowiak P, Goodlin-Jones B, Hertz-Picciotto I, Croen LA, Hansen RL. Sleep problems in children with autism spectrum disorders, developmental delays, and typical development: a population-based study. J Sleep Res. 2008;17:197-206.

5. Souders MC, Mason TB, Valladares O, Bucan M, Levy SE, Mandell DS, et al. Sleep behaviors and sleep quality in children with autism spectrum disorders. Sleep. 2009;32:1566-78.

6. Stein MA, Mendelsohn J, Obermeyer WH, Amromin J, Benca R. Sleep and behavior problems in school-aged children. Pediatrics. 2001;107:E60.

7. Owens JA, Spirito A, McGuinn M, Nobile C. Sleep habits and sleep disturbance in elementary school-aged children. J Dev Behav Pediatr. 2000;21:27-36.

8. Hvolby A. Associations of sleep disturbance with ADHD: implications for treatment. Atten Defic Hyperact Disord. 2014.

9. Sikora DM, Johnson K, Clemons T, Katz T. The relationship between sleep problems and daytime behavior in children of different ages with autism spectrum disorders. Pediatrics. 2012;130 Suppl 2:S83-90.

10. Goldman SE, Surdyka K, Cuevas R, Adkins K, Wang L, Malow BA. Defining the sleep phenotype in children with autism. Dev Neuropsychol. 2009;34:560-73.

11. Gail WP, Sears LL, Allard A. Sleep problems in children with autism. J Sleep Res. 2004;13:265-8.

12. Limoges E, Bolduc C, Berthiaume C, Mottron L, Godbout R. Relationship between poor sleep and daytime cognitive performance in young adults with autism. Res Dev Disabil. 2013;34: 1322-35.

13. Malow BA, Marzec ML, McGrew SG, Wang L, Henderson LM, Stone WL. Characterizing sleep in children with autism spectrum disorders: a multidimensional approach. Sleep. 2006;29:1563-71.

14. Allik H, Larsson JO, Smedje H. Sleep patterns of school-age children with Asperger syndrome or high-functioning autism. J Autism Dev Disord. 2006;36:585-95.

15. Wiggs L, Stores G. Sleep patterns and sleep disorders in children with autistic spectrum disorders: insights using parent report and actigraphy. Dev Med Child Neurol. 2004;46:372-80.

16. Giuditta A. Sleep memory processing: the sequential hypothesis. Front Syst Neurosci. 2014;8:219.

17. Buckley AW, Rodriguez AJ, Jennison K, Buckley J, Thurm A, Sato $\mathrm{S}$, et al. Rapid eye movement sleep percentage in children with autism compared with children with developmental delay and typical development. Arch Pediatr Adolesc Med. 2010;164: 1032-7.

18. Limoges E, Mottron L, Bolduc C, Berthiaume C, Godbout R. Atypical sleep architecture and the autism phenotype. Brain. 2005;128:1049-61.

19. American Academy of Sleep Medicine. International classification of sleep disorders - third edition (ICSD-3). Darien: American Academy of Sleep Medicine; 2014.
20. Glickman G. Circadian rhythms and sleep in children with autism. Neurosci Biobehav Rev. 2010;34:755-68.

21. Paavonen EJ, Raikkonen K, Lahti J, Komsi N, Heinonen K, Pesonen AK, et al. Short sleep duration and behavioral symptoms of attention-deficit/hyperactivity disorder in healthy 7- to 8-yearold children. Pediatrics. 2009;123:e857-64.

22. Pesonen AK, Raikkonen K, Paavonen EJ, Heinonen K, Komsi N, Lahti J, et al. Sleep duration and regularity are associated with behavioral problems in 8-year-old children. Int J Behav Med. 2010;17:298-305.

23. Humphreys JS, Gringras P, Blair PS, Scott N, Henderson J, Fleming PJ, et al. Sleep patterns in children with autistic spectrum disorders: a prospective cohort study. Arch Dis Child. 2014;99: 114-8.

24. Tan HL, Gozal D, Kheirandish-Gozal L. Obstructive sleep apnea in children: a critical update. Nat Sci Sleep. 2013;5:109-23.

25. Lee CH, Kang KT, Weng WC, Lee PL, Hsu WC. Quality of life after adenotonsillectomy in children with obstructive sleep apnea: short-term and long-term results. Int J Pediatr Otorhinolaryngol. 2015;79:210-5.

26. Hoban TF. Rhythmic movement disorder in children. CNS Spectr. 2003;8:135-8.

27. Simakajornboon N, Kheirandish-Gozal L, Gozal D. Diagnosis and management of restless legs syndrome in children. Sleep Med Rev. 2009;13:149-56.

28. Dauvilliers Y, Winkelmann J. Restless legs syndrome: update on pathogenesis. Curr Opin Pulm Med. 2013;19:594-600.

29. Goldman SE, Richdale AL, Clemons T, Malow BA. Parental sleep concerns in autism spectrum disorders: variations from childhood to adolescence. J Autism Dev Disord. 2012;42:531-8.

30. Ming X, Sun YM, Nachajon RV, Brimacombe M, Walters AS. Prevalence of parasomnia in autistic children with sleep disorders. Clin Med Pediatr. 2009;3:1-10.

31. Schreck KA, Mulick JA. Parental report of sleep problems in children with autism. J Autism Dev Disord. 2000;30:127-35.

32. Thirumalai SS, Shubin RA, Robinson R. Rapid eye movement sleep behavior disorder in children with autism. J Child Neurol. 2002;17:173-8.

33. Folstein S, Rutter M. Infantile autism: a genetic study of 21 twin pairs. J Child Psychol Psychiatry. 1977;18:297-321.

34. Hallmayer J, Cleveland S, Torres A, Phillips J, Cohen B, Torigoe $\mathrm{T}$, et al. Genetic heritability and shared environmental factors among twin pairs with autism. Arch Gen Psychiatry. 2011;68: 1095-102.

35. Buhr ED, Takahashi JS. Molecular components of the Mammalian circadian clock. Handb Exp Pharmacol. 2013;3-27.

36. Wimpory D, Nicholas B, Nash S. Social timing, clock genes and autism: a new hypothesis. J Intellect Disabil Res. 2002;46:352-8.

37. Nicholas B, Rudrasingham V, Nash S, Kirov G, Owen MJ, Wimpory DC. Association of Per1 and Npas2 with autistic disorder: support for the clock genes/social timing hypothesis. Mol Psychiatry. 2007;12:581-92.

38. Crocker A, Sehgal A. Genetic analysis of sleep. Genes Dev. 2010;24:1220-35.

39. Gadow KD, Pinsonneault JK, Perlman G, Sadee W. Association of dopamine gene variants, emotion dysregulation and ADHD in autism spectrum disorder. Res Dev Disabil. 2014;35:1658-65.

40. Veenstra-VanderWeele J, Muller CL, Iwamoto H, Sauer JE, Owens WA, Shah CR, et al. Autism gene variant causes hyperserotonemia, serotonin receptor hypersensitivity, social impairment and repetitive behavior. Proc Natl Acad Sci U S A. 2012;109:5469-74.

41. Gaetz W, Bloy L, Wang DJ, Port RG, Blaskey L, Levy SE, et al. GABA estimation in the brains of children on the autism spectrum: measurement precision and regional cortical variation. Neuroimage. 2014;86:1-9. 
42. Holst SC, Bersagliere A, Bachmann V, Berger W, Achermann P, Landolt HP. Dopaminergic role in regulating neurophysiological markers of sleep homeostasis in humans. J Neurosci. 2014;34: 566-73.

43. Hamilton PJ, Campbell NG, Sharma S, Erreger K, Herborg HF, Saunders C, et al. De novo mutation in the dopamine transporter gene associates dopamine dysfunction with autism spectrum disorder. Mol Psychiatry. 2013;18:1315-23.

44. Persico AM, Napolioni V. Autism genetics. Behav Brain Res. 2013;251:95-112.

45. Buhr A, Bianchi MT, Baur R, Courtet P, Pignay V, Boulenger JP, et al. Functional characterization of the new human $\operatorname{GABA}(\mathrm{A})$ receptor mutation beta3(R192H). Hum Genet. 2002;111:154-60.

46. Shao Y, Cuccaro ML, Hauser ER, Raiford KL, Menold MM, Wolpert CM, et al. Fine mapping of autistic disorder to chromosome $15 q 11-q 13$ by use of phenotypic subtypes. Am J Hum Genet. 2003;72:539-48.

47. Deuschle M, Schredl M, Schilling C, Wust S, Frank J, Witt SH, et al. Association between a serotonin transporter length polymorphism and primary insomnia. Sleep. 2010;33:343-7.

48. Prasad HC, Steiner JA, Sutcliffe JS, Blakely RD. Enhanced activity of human serotonin transporter variants associated with autism. Philos Trans R Soc Lond B Biol Sci. 2009;364:163-73.

49. Wang GY, Lee CG, Lee EJ. Genetic variability of arylalkylamine$\mathrm{N}$-acetyl-transferase (AA-NAT) gene and human sleep/wake pattern. Chronobiol Int. 2004;21:229-37.

50. Hu VW, Sarachana T, Kim KS, Nguyen A, Kulkarni S, Steinberg $\mathrm{ME}$, et al. Gene expression profiling differentiates autism casecontrols and phenotypic variants of autism spectrum disorders: evidence for circadian rhythm dysfunction in severe autism. Autism Res. 2009;2:78-97.

51. Connor JR, Wang XS, Allen RP, Beard JL, Wiesinger JA, Felt BT, et al. Altered dopaminergic profile in the putamen and substantia nigra in restless leg syndrome. Brain. 2009;132:2403-12.

52. Comings DE, Comings BG, Muhleman D, Dietz G, Shahbahrami $\mathrm{B}$, Tast $\mathrm{D}$, et al. The dopamine $\mathrm{D} 2$ receptor locus as a modifying gene in neuropsychiatric disorders. JAMA. 1991;266:1793-800.

53. Gehrman PR, Meltzer LJ, Moore M, Pack AI, Perlis ML, Eaves $\mathrm{LJ}$, et al. Heritability of insomnia symptoms in youth and their relationship to depression and anxiety. Sleep. 2011;34:1641-6.

54. Varju P, Katarova Z, Madarasz E, Szabo G. GABA signalling during development: new data and old questions. Cell Tissue Res. 2001;305:239-46.

55. Sanders SJ, Ercan-Sencicek AG, Hus V, Luo R, Murtha MT, Moreno-De-Luca D, et al. Multiple recurrent de novo CNVs, including duplications of the 7q11.23 Williams syndrome region, are strongly associated with autism. Neuron. 2011;70:863-85.

56. Kubas B, Kulak W, Sobaniec W, Tarasow E, Lebkowska U, Walecki J. Metabolite alterations in autistic children: a $1 \mathrm{H}$ MR spectroscopy study. Adv Med Sci. 2012;57:152-6.

57. Rojas DC, Singel D, Steinmetz S, Hepburn S, Brown MS. Decreased left perisylvian GABA concentration in children with autism and unaffected siblings. Neuroimage. 2014;86:28-34.

58. Winkelman JW, Buxton OM, Jensen JE, Benson KL, O'Connor SP, Wang W, et al. Reduced brain GABA in primary insomnia: preliminary data from $4 \mathrm{~T}$ proton magnetic resonance spectroscopy (1H-MRS). Sleep. 2008;31:1499-506.

59. Plante DT, Jensen JE, Winkelman JW. The role of GABA in primary insomnia. Sleep. 2012;35:741-2.

60. Mulder EJ, Anderson GM, Kema IP, de Bildt A, van Lang ND, den Boer JA, et al. Platelet serotonin levels in pervasive developmental disorders and mental retardation: diagnostic group differences, within-group distribution, and behavioral correlates. J Am Acad Child Adolesc Psychiatry. 2004;43:491-9.

61. Nakamura K, Sekine Y, Ouchi Y, Tsujii M, Yoshikawa E, Futatsubashi M, et al. Brain serotonin and dopamine transporter bindings in adults with high-functioning autism. Arch Gen Psychiatry. 2010;67:59-68.

62. Verma D, Chakraborti B, Karmakar A, Bandyopadhyay T, Singh AS, Sinha S, et al. Sexual dimorphic effect in the genetic association of monoamine oxidase A (MAOA) markers with autism spectrum disorder. Prog Neuropsychopharmacol Biol Psychiatry. 2014;50:11-20.

63. Monti JM. Serotonin control of sleep-wake behavior. Sleep Med Rev. 2011;15:269-81.

64. Ellis CM, Lemmens G, Parkes JD. Melatonin and insomnia. J Sleep Res. 1996;5:61-5.

65. de Faria PJ, Feltes BC, Bonatto D. Melatonin as a central molecule connecting neural development and calcium signaling. Funct Integr Genomics. 2011;11:383-8.

66. Bourgeron $\mathrm{T}$. The possible interplay of synaptic and clock genes in autism spectrum disorders. Cold Spring Harb Symp Quant Biol. 2007;72:645-54

67. Tordjman S, Anderson GM, Pichard N, Charbuy H, Touitou Y. Nocturnal excretion of 6-sulphatoxymelatonin in children and adolescents with autistic disorder. Biol Psychiatry. 2005;57:134-8.

68. Kulman G, Lissoni P, Rovelli F, Roselli MG, Brivio F, Sequeri P. Evidence of pineal endocrine hypofunction in autistic children. Neuro Endocrinol Lett. 2000;21:31-4.

69. Nir I, Meir D, Zilber N, Knobler H, Hadjez J, Lerner Y. Brief report: circadian melatonin, thyroid-stimulating hormone, prolactin, and cortisol levels in serum of young adults with autism. J Autism Dev Disord. 1995;25:641-54.

70. Melke J, Goubran BH, Chaste P, Betancur C, Nygren G, Anckarsater $\mathrm{H}$, et al. Abnormal melatonin synthesis in autism spectrum disorders. Mol Psychiatry. 2008;13:90-8.

71. Ackermann K, Stehle JH. Melatonin synthesis in the human pineal gland: advantages, implications, and difficulties. Chronobiol Int. 2006;23:369-79.

72. Jonsson L, Ljunggren E, Bremer A, Pedersen C, Landen M, Thuresson K, et al. Mutation screening of melatonin-related genes in patients with autism spectrum disorders. BMC Med Genomics. 2010;3:10

73. Cai G, Edelmann L, Goldsmith JE, Cohen N, Nakamine A, Reichert JG, et al. Multiplex ligation-dependent probe amplification for genetic screening in autism spectrum disorders: efficient identification of known microduplications and identification of a novel microduplication in ASMT. BMC Med Genomics. 2008;1:50

74. Arendt J. Melatonin and the pineal gland: influence on mammalian seasonal and circadian physiology. Rev Reprod. 1998;3:13-22.

75. Braam W, Keijzer H, Struijker BH, Didden R, Smits M, Curfs L. CYP1A2 polymorphisms in slow melatonin metabolisers: a possible relationship with autism spectrum disorder? J Intellect Disabil Res. 2013;57:993-1000.

76. Veatch OJ, Pendergast JS, Allen MJ, Leu RM, Johnson CH, Elsea $\mathrm{SH}$, Malow BA. Genetic variation in melatonin pathway enzymes in children with autism spectrum disorder and comorbid sleep onset delay. J Autism Dev Disord. 2014.

77. Dhawan V, Ali M, Chaudhuri KR. Genetic aspects of restless legs syndrome. Postgrad Med J. 2006;82:626-9.

78. Earley CJ, Connor J, Garcia-Borreguero D, Jenner P, Winkelman $\mathrm{J}$, Zee PC, et al. Altered Brain iron homeostasis and dopaminergic function in Restless Legs Syndrome (Willis-Ekbom Disease). Sleep Med. 2014;15:1288-301.

79. Connor JR, Wang XS, Patton SM, Menzies SL, Troncoso JC, Earley CJ, et al. Decreased transferrin receptor expression by neuromelanin cells in restless legs syndrome. Neurology. 2004;62:1563-7.

80. Sidrak S, Yoong T, Woolfenden S. Iron deficiency in children with global developmental delay and autism spectrum disorder. J Paediatr Child Health. 2014;50:356-61. 
81. Dosman CF, Brian JA, Drmic IE, Senthilselvan A, Harford MM, Smith RW, et al. Children with autism: effect of iron supplementation on sleep and ferritin. Pediatr Neurol. 2007;36:152-8.

82. Allen R. Dopamine and iron in the pathophysiology of restless legs syndrome (RLS). Sleep Med. 2004;5:385-91.

83. Malow BA, Byars K, Johnson K, Weiss S, Bernal P, Goldman SE, et al. A practice pathway for the identification, evaluation, and management of insomnia in children and adolescents with autism spectrum disorders. Pediatrics. 2012;130 Suppl 2:S106-24.

84. Reynolds AM, Malow BA. Sleep and autism spectrum disorders. Pediatr Clin North Am. 2011;58:685-98.

85. McPheeters ML, Warren Z, Sathe N, Bruzek JL, Krishnaswami S, Jerome RN, et al. A systematic review of medical treatments for children with autism spectrum disorders. Pediatrics. 2011;127: e1312-21.

86. Scott LJ, Dhillon S. Risperidone: a review of its use in the treatment of irritability associated with autistic disorder in children and adolescents. Paediatr Drugs. 2007;9:343-54.

87. Megens AA, Awouters FH, Schotte A, Meert TF, Dugovic C, Niemegeers CJ, et al. Survey on the pharmacodynamics of the new antipsychotic risperidone. Psychopharmacology (Berl). 1994;114:9-23.

88. Dinnissen M, Dietrich A, van den Hoofdakker BJ, Hoekstra PJ. Clinical and pharmacokinetic evaluation of risperidone for the management of autism spectrum disorder. Expert Opin Drug Metab Toxicol. 2015;11:111-24.

89. Kolevzon A, Mathewson KA, Hollander E. Selective serotonin reuptake inhibitors in autism: a review of efficacy and tolerability. J Clin Psychiatry. 2006;67:407-14.

90. DeMartinis N, Winokur A. The effects of antidepressants on sleep: the good and the bad. Psychiatr Times. 2012;29.

91. Porter A. Sleep problem in autism spectrum disorders. New York: Oxford University Press; 2011.

92. Braam W, Smits MG, Didden R, Korzilius H, Van Geijlswijk IM, Curfs LM. Exogenous melatonin for sleep problems in individuals with intellectual disability: a meta-analysis. Dev Med Child Neurol. 2009;51:340-9.

93. Cummings $\mathrm{C}$. Melatonin for the management of sleep disorders in children and adolescents. Paediatr Child Health. 2012;17:331-6.

94. Giannotti F, Cortesi F, Cerquiglini A, Bernabei P. An open-label study of controlled-release melatonin in treatment of sleep disorders in children with autism. J Autism Dev Disord. 2006;36:741-52.

95. Goldman SE, Adkins KW, Calcutt MW, Carter MD, Goodpaster RL, Wang L, et al. Melatonin in children with autism spectrum disorders: endogenous and pharmacokinetic profiles in relation to sleep. J Autism Dev Disord. 2014;44:2525-35.

96. Malow B, Adkins KW, McGrew SG, Wang L, Goldman SE, Fawkes D, et al. Melatonin for sleep in children with autism: a controlled trial examining dose, tolerability, and outcomes. J Autism Dev Disord. 2012;42:1729-37.

97. Rossignol DA, Frye RE. Melatonin in autism spectrum disorders: a systematic review and meta-analysis. Dev Med Child Neurol. 2011;53:783-92.

98. Cortesi F, Giannotti F, Sebastiani T, Panunzi S, Valente D. Controlled-release melatonin, singly and combined with cognitive behavioural therapy, for persistent insomnia in children with autism spectrum disorders: a randomized placebo-controlled trial. J Sleep Res. 2012;21:700-9.

99. Ming X, Gordon E, Kang N, Wagner GC. Use of clonidine in children with autism spectrum disorders. Brain Dev. 2008;30: 454-60.

100. Posey DJ, Guenin KD, Kohn AE, Swiezy NB, McDougle CJ. A naturalistic open-label study of mirtazapine in autistic and other pervasive developmental disorders. J Child Adolesc Psychopharmacol. 2001;11:267-77.
101. Robinson AA, Malow BA. Gabapentin shows promise in treating refractory insomnia in children. J Child Neurol. 2013;28:1618-21.

102. Aman MG, Arnold LE, McDougle CJ, Vitiello B, Scahill L, Davies M, et al. Acute and long-term safety and tolerability of risperidone in children with autism. J Child Adolesc Psychopharmacol. 2005;15:869-84.

103. Chervin RD, Ruzicka DL, Giordani BJ, Weatherly RA, Dillon JE, Hodges EK, et al. Sleep-disordered breathing, behavior, and cognition in children before and after adenotonsillectomy. Pediatrics. 2006;117:e769-78.

104. Marcus CL, Moore RH, Rosen CL, Giordani B, Garetz SL, Taylor $\mathrm{HG}$, et al. A randomized trial of adenotonsillectomy for childhood sleep apnea. N Engl J Med. 2013;368:2366-76.

105. Bhattacharjee R, Kheirandish-Gozal L, Spruyt K, Mitchell RB, Promchiarak J, Simakajornboon N, et al. Adenotonsillectomy outcomes in treatment of obstructive sleep apnea in children: a multicenter retrospective study. Am J Respir Crit Care Med. 2010;182:676-83.

106. Marcus CL, Brooks LJ, Draper KA, Gozal D, Halbower AC, Jones J, et al. Diagnosis and management of childhood obstructive sleep apnea syndrome. Pediatrics. 2012;130:e714-55.

107. Brandwein AB, Foxe JJ, Butler JS, Frey HP, Bates JC, Shulman LH, Molholm S. Neurophysiological indices of atypical auditory processing and multisensory integration are associated with symptom severity in Autism. J Autism Dev Disord. 2014.

108. Slifer KJ, Avis KT, Frutchey RA. Behavioral intervention to increase compliance with electroencephalographic procedures in children with developmental disabilities. Epilepsy Behav. 2008;13:189-95.

109. Villa MP, Castaldo R, Miano S, Paolino MC, Vitelli O, Tabarrini A, et al. Adenotonsillectomy and orthodontic therapy in pediatric obstructive sleep apnea. Sleep Breath. 2014;18:533-9.

110. Kline CE, Crowley EP, Ewing GB, Burch JB, Blair SN, Durstine $\mathrm{JL}$, et al. The effect of exercise training on obstructive sleep apnea and sleep quality: a randomized controlled trial. Sleep. 2011;34: 1631-40.

111. Daftary AS, Kotagal S. Treatment of childhood obstructive sleep apnea. Curr Treat Options Neurol. 2010;12:369-78.

112. Brouillette RT, Manoukian JJ, Ducharme FM, Oudjhane K, Earle LG, Ladan S, et al. Efficacy of fluticasone nasal spray for pediatric obstructive sleep apnea. J Pediatr. 2001;138:838-44.

113. Goldbart AD, Goldman JL, Veling MC, Gozal D. Leukotriene modifier therapy for mild sleep-disordered breathing in children. Am J Respir Crit Care Med. 2005;172:364-70.

114. Kheirandish L, Goldbart AD, Gozal D. Intranasal steroids and oral leukotriene modifier therapy in residual sleep-disordered breathing after tonsillectomy and adenoidectomy in children. Pediatrics. 2006;117:e61-6.

115. Weiss M, Owens J. Recognizing pediatric sleep apnea. Nurse Pract. 2014;39:43-9.

116. Sharp WG, Berry RC, McCracken C, Nuhu NN, Marvel E, Saulnier CA, et al. Feeding problems and nutrient intake in children with autism spectrum disorders: a meta-analysis and comprehensive review of the literature. J Autism Dev Disord. 2013;43: 2159-73.

117. Allen RP. Restless legs syndrome/Willis Ekbom disease: evaluation and treatment. Int Rev Psychiatry. 2014;26:248-62.

118. Vendrame M, Zarowski M, Loddenkemper T, Steinborn B, Kothare SV. Selective serotonin reuptake inhibitors and periodic limb movements of sleep. Pediatr Neurol. 2011;45:175-7.

119. Mason TB, Pack AI. Pediatric parasomnias. Sleep. 2007;30: 141-51.

120. Robinson A, Guilleminault C. Disorders of arousal. In: Chokroverty SH, Walters A, editors. Sleep and movement disorders. Philadelphia: Butterworth Heinemann; 2003. p. 265-72. 